\title{
A NEW CONSISTOMETER AND ITS APPLICATION TO GREASES AND TO OILS AT LOW TEMPERATURES ${ }^{1}$
}

\author{
By Ronald Bulkley and F. G. Bitner
}

\section{ABSTRACT}

A consistometer is described which is suitable for determining the consistency of viscous and plastic materials in general, but which is more particularly advantageous in obtaining flow-pressure diagrams for materials which change rapidly in consistency with time or which show a breakdown of structure with mechanical working. The limitations of some commonly used instruments are discussed, and the sources of error in the present instrument are pointed out. Flow-pressure graphs of a cup grease at different temperatures and of various plastic oils at $0^{\circ} \mathrm{C}$. are shown.

The importance and the significance of the unworked consistency of the undisturbed material and of the thoroughly worked consistency of the completely broken down material are discussed. The method of measuring these properties of the material with the new instrument are described in detail.

\section{CONTENTS}

Page.

I. Introduction

II. Description of the instrument

III. Manner of operation.

IV. Calibration of capillaries

V. Some advantages of the instrument

VI. Flow-pressure graphs of plastic lubricants

VII. Conclusions

\section{INTRODUC'TION}

The consistometer to be described here is rugged, simple of construction, speedy in operation, and can be employed for either opaque or clear materials of a wide range of consistencies. It also possesses two features which are unusual in a consistometer, but which are of great importance in the testing of all such plastic materials as show a breakdown of structure with working, or which change in consistency with time.

The first of these features is that the test material may be passed successively back and forth through the capillary any number of times. $^{2}$ The second is that determinations of the rate of flow are made by passing only a very small volume of material through the capillary, thus minimizing the breakdown effect of the working which is incident to the measurement itself.

With the aid of these two features the unworked, as well as the thoroughly worked, consistency of the material may be closely approximated. With such forms of instrument as permit of flow in one direction only, and for which a large amount of material must be passed through the capillary for a single datum point, neither the unworked

1 This paper was presented at the meeting of the Society of Rheology held at Washington, D. C., Dec. 19 and $20,1929$.

'Another consistometer embodying this feature has recently been described by Scott Blair, The Flow If Clay Pastes Through Narrow Tubes, J. Phys. Chem., 33, pp. 321-330; 1929. This paper first came to pur attention about a year after our own instrument had beon put into use, 
nor the worked consistency is obtained, but only an intermediate consistency on partially worked and constantly changing material. The first of the two special features also makes it possible to obtain flow-pressure graphs at a number of temperatures with a single filling: of the instrument, or without removing the instrument from the bath. There are no weighings to be performed and no auxiliary apparatus is required, such as pressure tanks, pressure regulators, etc.

\section{DESCRIPTION OF THE INSTRUMEN'T}

The complete apparatus dismounted for photographing, together with all auxiliary appliances and two extra capillaries, is shown in Figure 1. Figure 2 is a schematic representation of the instrument in operation.

Referring to Figure 2, the device shown on the right is a mercury leveling bulb equipped with two stopcocks and with a side arm of

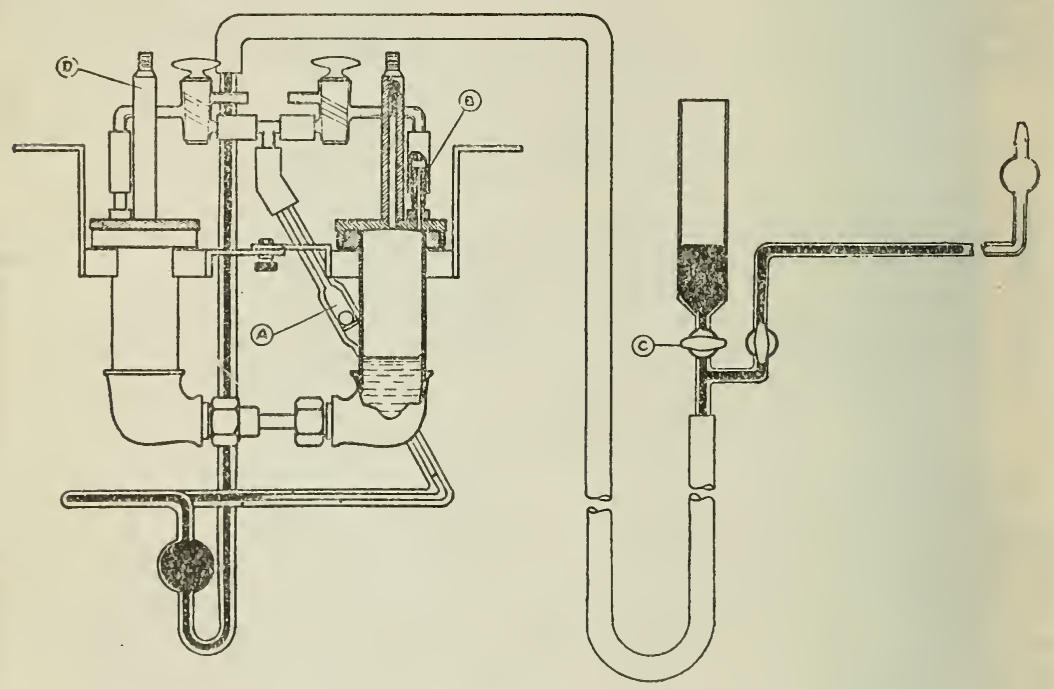

FIGURE 2.- Schematic representaition of instrument in operation

small-bore glass tubing. Since the movement of the mercury surface in this tubing shows the volume of flow of the test material, the volume of mercury per unit length of the tube must be determined. If clean mercury is employed and if the pressure tubing of the system is of high-grade sulphur-free rubber, the bore of the glass side arm may safely be as great as $2.5 \mathrm{~mm}$, without causing the mercury surface to assume an irregular form. This part of the apparatus is mounted on a clamp stand outside the bath. The side arm must be accurately horizontal.

The ball float valve $A$ serves to prevent the passage of mercury into the consistometer in case of a sudden leak in the apparatus. It is joined to a second horizontal tube and then to a gooseneck with a safety bulb, and is connected by pressure tubing to the leveling device outside the bath. Merely to conserve space, it is bent at an angle to the horizontal tube below it. When this tube has been leveled, 
B. S. Journal of Research, RP188

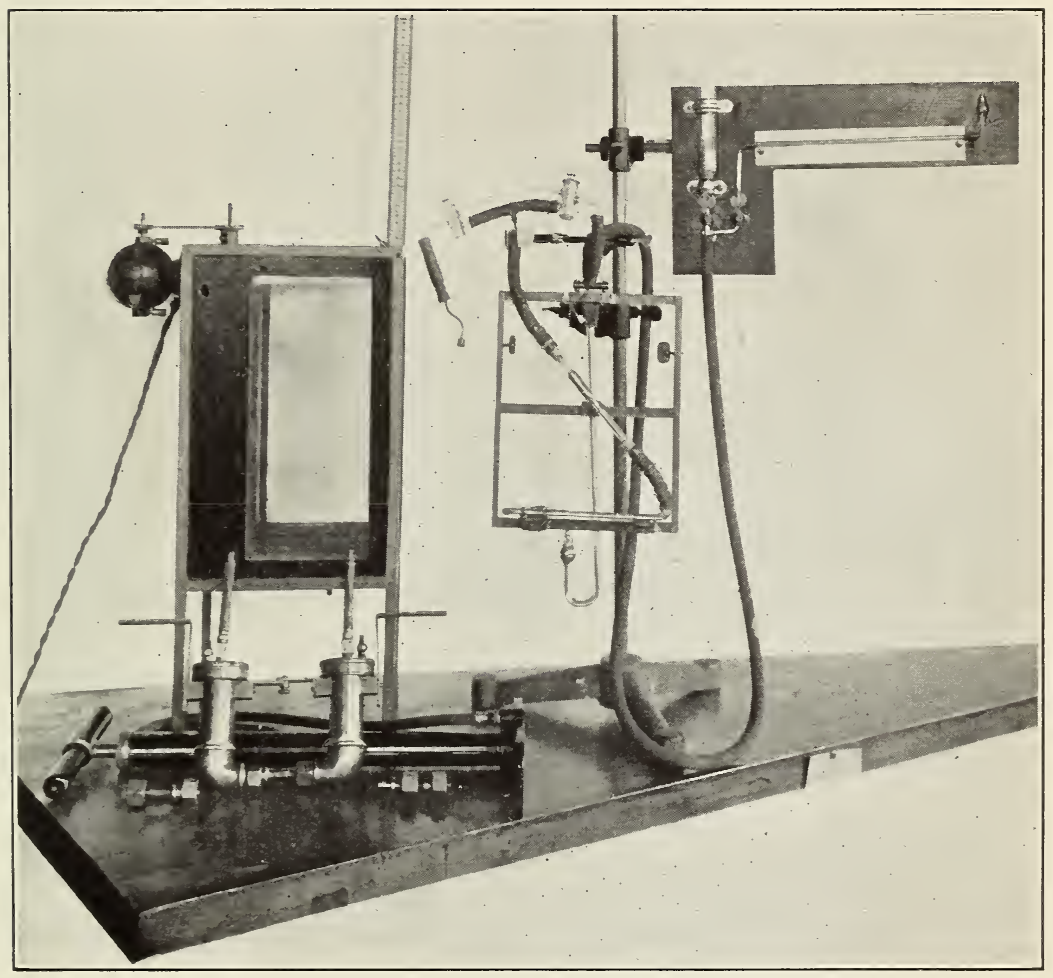

FIgURE 1.-Bulkley consistometer and accessories 
the frame on which the piece is mounted is clamped rigilly in position in the bath once for all. The head of inereury effective in producing flow is the vertical distance between the two horizontal tubes, and is measured on a millimeter scale attached to the bath.

The consistometer proper is made entirely of metal. It consists essentially of two similarly constructed reservoirs to contain the test material, joined at the bottom by the capillary through which the flow is to be measured, and fitted with screw covers having suitable outlets for pressure connections. The instrument is hung in the bath by side arms of brass straps. Similar straps connect the two containers at the top. The capacity of each container need not be greater than $25 \mathrm{~cm}^{3}$.

The capillaries are interchangeable. They are equipped on one end with a rigidly attached hexagonal nut and on the other with a collar and gland nut, which permits ready dismounting and reassembling of the instrument.

Each cover has two openings. The one centrally placed is closed by an ordinary automobile tire valve, while the other is joined through a 3-way stopcock to the mercury float valve.

\section{MANNER OF OPERATION}

Sufficient mercury is poured into the leveling bulb to fill the pressure system from some point on the lower horizontal tube to a corresponding point on the upper tube, as shown in Figure 2. At higher pressures slightly more mercury will be required than at low pressures, on account of the expansion of the rubber tubing. This adjustment of the mercury volume is very easily and quickly made through the leveling bulb in either direction as desired. Most of the mercury remains permanently in the pressure system for several months or until fouled.

To prevent blowing air through the capillary and to reduce the total volume of air in the apparatus, slightly more of the test material should be put into the consistometer than the amount required to fill one container. Suppose the left-hand container to be more than half full and the right one to be less than half full of the material to be tested. The covers are fitted tightly, the instrument is suspended in the bath and connected to the pressure system through the flexible joints $B$. When all is in readiness for a run, both cocks of the leveling device being open, the 3 -way cocks above the float valve $A$ are turned into such position as to connect both containers of the instrument with $A$. The leveling device is raised sufficiently to give a head of mercury equivalent to the highest pressure desired in the run. By a tire pump, pressure is now applied through either of the tire valves $D$. There will be no appreciable flow of the test material during this procedure, since the air pressure will be equal in both containers, but the mercury in $A$ will be forced out and up in to the leveling device. When the pressure is just great enough to keep the mercury surfaces in the two horizontal tubes, stopcock $C$ is closed. Flow of the test material through the capillary is started by relieving the pressure in the right-hand container of the instrument by connecting this container to the atmosphere through its 3-way stopcock. The test material flows through the capillary of the consistometer from left to right. As flow proceeds the mercury surface in the lower hori- 
zontal tube of the pressure system moves to the right, that in the upper tube to the left. Conditions at this instant are depicted in Figure 2.

Since the two horizontal tubes are approximately $2.5 \mathrm{~mm}$ in diameter, no correction for the surface tension of the mercury is required. The slight pressure resulting from the difference of level of the test material in the two containers may be neglected except in the work of calibration and in such instances as demand the highest accuracy.

The volume of flow of test material is equal to the volume of mercury displaced after the run has commenced. The rate of flow is therefore calculated by timing the motion of the upper mercury surface along a scale mounted behind the side arm. The volume of flow for one point on the flow-pressure graph need not be greater than $0.5 \mathrm{~cm}^{3}$ to procure ample accuracy of measurement. After the time reading has been taken the run is allowed to proceed while the head is being measured and while the data are being recorded. To obtain a reading at a second pressure, it is not necessary to use the pump again or to disturb the setting of the stopcock. The leveling bulb is simply lowered to such a position that the mercury surfaces are again in the proper portions of the horizontal tubes, when the frame is again clamped into position and the rate of flow again timed.

By the above procedure data for a great many points are obtained very speedily. If the air pressure in the system is partially relieved between runs by manipulating one of the 3-way stopcocks, greater decrements of pressure result. This method of operation is, perhaps, preferable to the first, since a much greater range of pressures may be covered in a given length of time.

Data for the first flow-pressure relation having been obtained, those for any number of others at the same temperature or at other temperatures may be obtained by forcing the material back and forth through the capillary, taking readings as the material flows in either direction.

If the material is a simple viscous liquid or if no concern is felt as to a possible breakdown in structure with working, the time required to establish thermal equilibrium before commencing the first run may be greatly lessened by forcing the material through the capillary with the pump. During this procedure the float valve and leveling bulb are cut out by the appropriate stopcock to permit the use of higher pressures. As the material passes through the capillary it is exposed to its environment in a thin stream, and in only one or two passages it has all acquired the proper test temperature.

\section{CALIBRATION OF CAPILLARIES}

A method which is frequently employed for the calibration of the diameter of large capillary tubes, such as are ordinarily used for plastic materials, is the direct microscopic examination of the ends of the tube. This method, however, involves the somewhat doubtful assumption that the mean of the observed diameters of the two ends is the true effective diameter under conditions of flow.

A more reliable method ${ }^{3}$ consists in calculating the true effective diameter from the results of flow tests with liquids of known viscosity.

Herschel and Bulkley, Calibration of the Buret Consistometer. Ind. \& Eng. Chem., 19, pp. 134-139; 
This procedure seems particularly commendable in the present instance, where it is desired to check not only the diameter of the capillary but also the general performance of the apparatus as a whole.

Figures 3 and 4 show flow-pressure graphs for two capillaries for mineral oils whose viscosity at the different temperatures had been determined on a Bingham viscometer. The general accuracy of the data may be inferred from the manner in which the points fall upon a straight line passing through the origin. From the slope of each

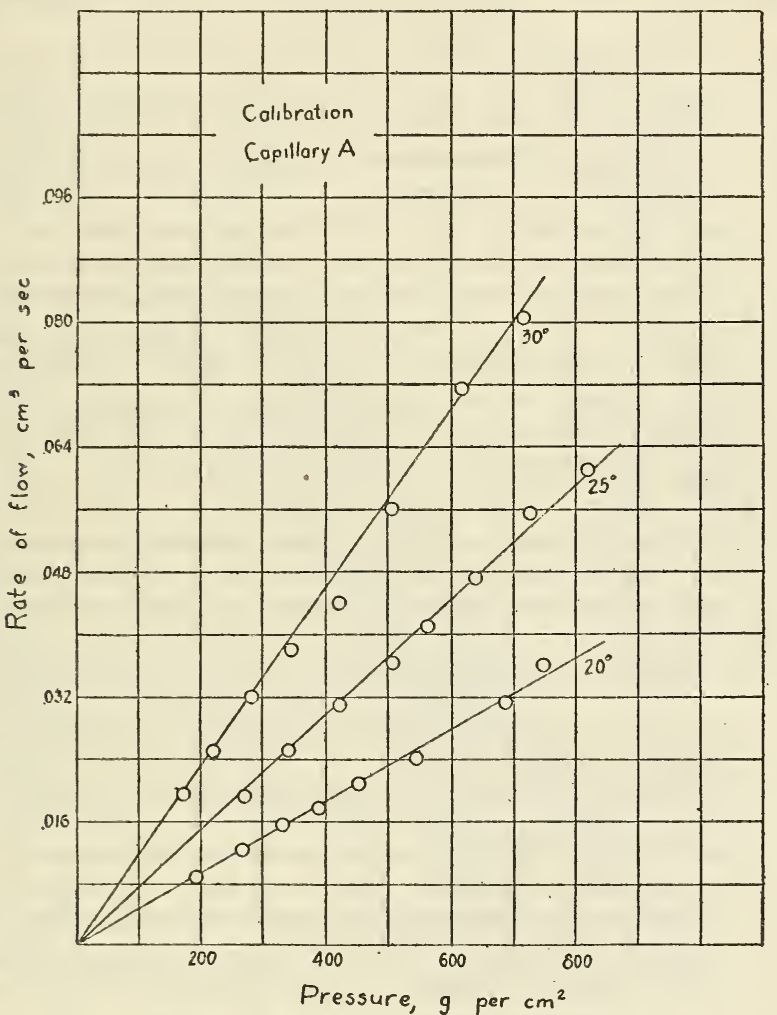

FIgURE 3.-Calibration graphs for capillary $A$

graph the diameter of the capillary may be calculated and compared with the diameter as measured directly. Since the kinetic energy correction is negligible here, we write from the ordinary equation for viscous flow

$$
d^{4} / l=\frac{128 \mu}{\pi g}\left(\frac{q}{p}\right)
$$

where

$\mu=$ viscosity in poises.

$d=$ diameter of capillary, $\mathrm{cm}$.

$l=$ length of capillary, $\mathrm{cm}$.

$g=$ acceleration of gravity, $\mathrm{cm} / \mathrm{sec}^{2}$.

$q=$ rate of flow, $\mathrm{cm}^{3}$ per sec.

$p=$ pressure difference producing flow, g per $\mathrm{cm}^{2}$. 
The quotient, $q / p$, is obtained directly from the diagram as the slope of the flow-pressure graph.

The agreement between values of $d^{4} / l$ as calculated from different graphs for the same capillary is an index of the dependability of the apparatus and general procedure. The following table shows the agreement which is obtained between values of this quotient as calculated from flow tests and from direct measurement. The values calculated from the graphs are considered the more reliable and have been used in later work. All of the data for the three graphs of Figure

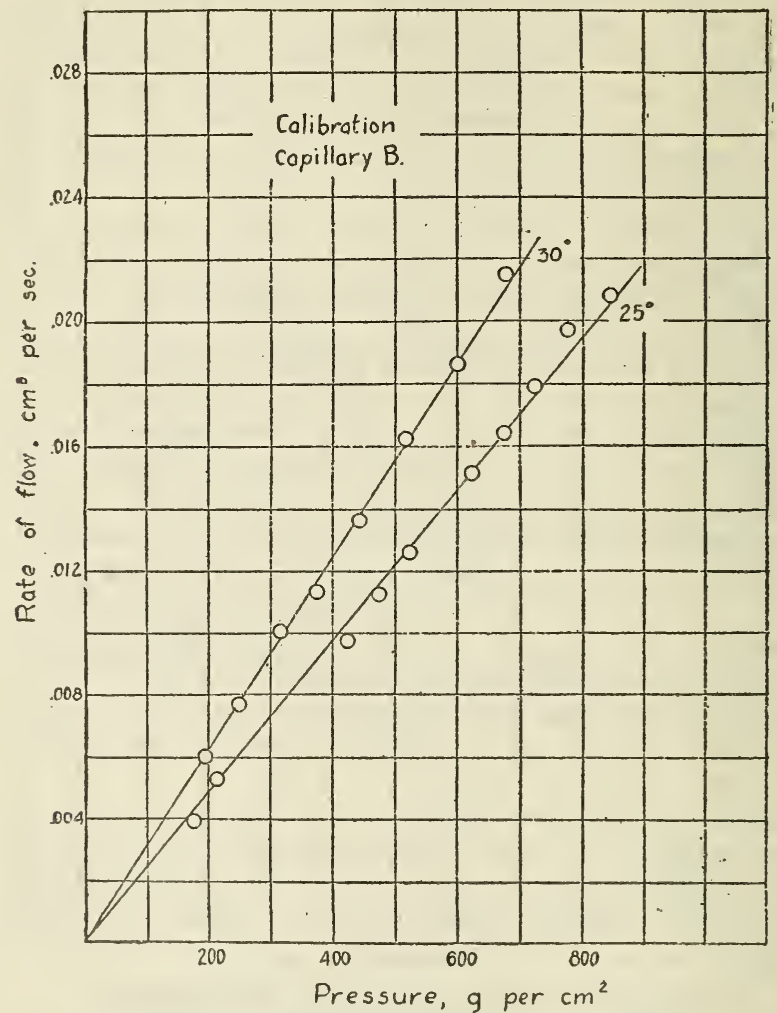

FigURE 4.-Calibration graphs for capillary $B$

3 were obtained without removing the instrument from the bath. The same is true for the two graphs of Figure 4.

\begin{tabular}{|c|c|c|c|c|c|}
\hline 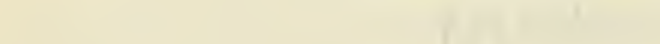 & \multicolumn{3}{|c|}{ Capillary A } & \multicolumn{2}{|c|}{ Capillary B } \\
\hline & $20^{\circ} \mathrm{C}$ & $25^{\circ} \mathrm{C}$. & $30^{\circ} \mathrm{C}$. & $25^{\circ} \mathrm{C}$. & $30^{\circ} \mathrm{C}$. \\
\hline $\begin{array}{l}\text { Viscosity of oil poises } \\
g / p \times 10^{5} \\
d^{4} / l \times 10^{7} \text {, calculated }\end{array}$ & $\begin{array}{c}49.7 \\
\quad 4.61 \\
952\end{array}$ & $\begin{array}{c}30.7 \\
7.41 \\
945\end{array}$ & $\begin{array}{l}19.5 \\
11.4 \\
924\end{array}$ & $\begin{array}{l}0.560 \\
2.44 \\
5.68\end{array}$ & $\begin{array}{l}0.429 \\
3.12 \\
5.56\end{array}$ \\
\hline $\begin{array}{l}\text { Average } d^{4} / l \times 10^{7} \text {, calculated } \\
\text { Measured length, centimoters } \\
\text { Measured diameter, centimeters. } \\
d^{4} / l \times 10^{7} \text { from measured diameter and lengt }\end{array}$ & \multicolumn{3}{|c|}{$\begin{array}{l}940.4 \\
7.54 \\
936\end{array}$} & \multicolumn{2}{|c|}{$\begin{array}{l}\text { 5. } 620 \\
7.39 \\
.0445 \\
\text { 5. } 31\end{array}$} \\
\hline
\end{tabular}




\section{SOME ADVANTAGES OF THE INSTRUMENT AND SOME SOURCES OF ERROR}

Of the rarious devices commonly employed for determining the consistency of a plastic material, the capillary-tube type of instrument has been more thoroughly investigated than any other, both experimentally and from a theoretical point of view. Many forms of this type of instrument are in use, but practically all of them are suitable only for such materials as show no change of consistency either with time or with mechanical working.

F. L. Browne and Don Brouse ${ }^{4}$ have emphasized the importance of the change of casein glue with time, and have shown the limitations of the Herschel consistometer for this kind of material. The same disadvantages are inherent in the Bingham and Green plastometer, of which the Fierschel instrument is a modification. In a later paper Brouse ${ }^{5}$ has also mentioned the necessity for testing over a vide range of temperatures. For the above instruments a period of two hours in the bath is required after each change of temperature for the material to acquire the temperature of test. Casein glue is only one example of a great variety of substances which show a more or less rapid change of consistency with time, and flow-pressure graphs of other plastic materials are frequently desired at several temperatures. While the ideal instrument "with which measurements of flow under several different pressures can be made simultaneously" is not realized in the present case, the consistometer used by the present authors, nevertheless, does permit the worked material to be brought in a few minutes to the test temperature, and data for five or six points on a flow-pressure graph can then be obtained in approximately the same time as required for a single point by the instrument Browne and Brouse employed.

Theoretically, an instrument equipped with a flow meter, after the manner of Henry Green, ${ }^{6}$ gives an instantaneous reading of the rate of flow. Practically, however, this offers very little saving of time in procuring data because of the relatively large amount of time which must still be used in taking readings, adjusting the pressure, etc. The calibration of a flow meter of the Green type is laborious, and a separate thermostat for the flow meter is desirable, if not utterly essential, where tests are to be conducted at more than one temperature. The calibration of the horizontal measuring tube of the present instrument is exceedingly simple, and the readings of rate of flow are obtained in a short enough time to make the instrument satisfactory for the testing of rapidly changing materials as weil as materials which break down in structure with working.

P. M. Giessey and S. Arzoomanian ${ }^{7}$ have described a modification of the simple buret consistometer whereby the principle of the latter instrument may be applied to stiff substances, such as greases and dental pastes. The material used by these investigators possessed "some structure," and on making a check run on material which remained in the instrument from a previous determination they found an increase of 50 per cent in the mobility. This very considerable

1 The Consistency of Casein Glue, Colloid Symposium Monograph, 5, pp. 222-242; 1928.

$\checkmark$ Consistency of A nimal Glue, Ind. \& Eng. Chem., 21, pp. 242-247; 1929.

6 Further development of the Plastometer and Its Practical Application to Research and Routine Problems, Proc. Am. Soc. Test. Mats., 20, pt. 2, pp. 451-494; 1920.

7 A New Rapid Extrusion Plastometer, Colloid Symposium Monograph, 5, pp. 253-258; 1928. 
change in consistency had evidently been produced by mechanical working of the material in the container of the instrument while the first run was proceeding. Presumably a much greater breakdown of structure would have been noted had the material been tested again after its passage through the capillary, where the shearing is much more severe than in the container. The indications are therefore that the first run, certainly, and the check run, perhaps, were both made on material which was constantly changing. In this event neither run truly represents the consistency either of the unworked or the thoroughly worked material.

This instance is cited not as a criticism of a particular investigation, but merely as an example of the practice, which has been more or less common in the past, of submitting a material possessing structure to a single passage through the capiliary. The results of such a procedure are usually of little practical value, since, in general, either the unworked or the thoroughly worked consistency is desired. Thus when starting an engine in cold weather, if the oil is congealed in the feed lines and bearings, its unworked consistency is of paramount importance. After a few minutes' running, however, the structure of the oil is completely broken down and the worked consistency is desired. The consistency in an intermediate condition is of little significance.

For many materials this breakdown of structure is, of course, weil recognized, and in the case of greases the American Society for Testing Materials ${ }^{8}$ has tentatively specified a definite procedure for working the material before test. The structure may be present in many other materials, however, where its existence would remain unsuspected unless tested for directly. It is known to develop in certain paint pastes, ${ }^{9}$ and in enamel slips containing a small percentage of clay, if these materials are allowed to stand undisturbed for some time after working. As will be shown later, oils which have become plastic at a low temperature also manifest this behavior. The same phenomenon has been observed in the case of many other colloidal systems by Freundlich ${ }^{10}$ and has been called by him thixotropy.

Strictly speaking, the experimental determination of the unworked consistency of a plastic material is an impossibility. It is conceivable that some method of testing could be devised wliereby the unworked consistency could be approximated through a backward extrapolation. A more practical expedient, and one which gives a sufficiently accurate approximation for many purposes, is to make several observations of the rate of flow over a range of pressures by the passage of only a small amount of material through the capillary. As shown by Giesy and Arzoomanian, and as will be shown here later, the breakdown of structure in the container is often so great that when several grams of material are passed for a single datum point even an approximation of the unworked consistency is impossible.

If a material increases in stiffness only slowly after working, its thoroughly worked consistency may be determined at room tem-

\footnotetext{
8 Tentative Metlod of Test for Penetration of Greases, Proc. Am. Soc. Test. Mats., 26, pt. 1, pp. 834-839; 1926 .

II. I. Beakes, Settling of Pigments in House Paints, Ind. \& Eng. Chem., 21, pp. 1118-1121; 1929.

10 If. Fremndlich and L. L. Bircumshau, Thixotropic Behavior of Aluminum Hydroxide Gels, Kolloid \%., 10, р. 19-22; 1936.
} 
perature on practically any of the instruments commonly employed. When the plastic properties exist largely as a result of cooling, however, as in the case of a frozen oil or gelatin, the broken-down consistency in the cooled condition can be measured only with an instrument in which the material is maintained at the test temperature continuously while being worked and tested. The effects of any working received by a plastic oil at $0^{\circ} \mathrm{C}$., for instance, are completely destroyed by exposing the oil to the temperature of the room while weighing the oil and returning it to the consistometer, as must be done in the Bingham instrument and its various modifications.

The instrument herein described is well adapted for the purpose of determining the consistency of plastic materials in general, and more particularly for the special materials considered in this section. It is also suitable for the determination of the viscosity of true liquids which are too opaque or too viscous to be handled readily in viscometers of the Ostwald or the Bingham type. At the present time there is a great dearth of instruments with which viscosities higher than 30 or 40 poises can be measured to an accuracy of 5 per cent without an excessive consumption of time. With the present instrument the rapid measurement of viscosities of several thousands of poises to an accuracy of \pm 2 per cent is entirely feasible.

The chief source of error in the instrument is the change of volume which is brought about in the air in the system by a change either of temperature or of pressure. Since the volume of flow which is measured is small, a given percentage change in the volume of air during a test produces a relatively large percentage error in the observed rate of flow.

As a numerical example, if the total volume of the air in the apparatus is $20 \mathrm{~cm}^{3}$ and if the head of mercury producing flow is $24 \mathrm{~cm}$, then for a volume of flow of $1 \mathrm{~cm}^{3}$ a change of pressure of $1 \mathrm{~mm}$ of mercury will result in a 2 per cent error in the observed rate of flow if the change takes place during the timed interval. Similarly, a change of temperature of $0.1^{\circ} \mathrm{C}$. during a timed interval produces an error of about 0.8 per cent in the observed rate of flow. This emphasizes the necessity for using great care in leveling the horizontal tubes and in accurately controlling the temperature of the bath. It also indicates the desirability of having the volume of air in the system as small as practicable.

\section{FLOW-PRESSURE GRAPHS OF PLASTIC LUBRICANTS}

The data for the graphs shown in this section were taken on an earlier form of the instrument in which a safety reservoir was employed in place of the float valve. The degree of accuracy of the data is therefore not as high as that obtained in the calibration of the capillaries. ${ }^{11}$ In most cases the graphs are straight lines throughout the greater portion of their length, and the method of treatment proposed by Bingham ${ }^{12}$ is apparently the most satisfactory for obtaining numerical constants for the consistency of the material. However, since the present purpose is merely to illustrate the utility of the instrument in procuring consistency data, discussion of the significance of these constants in lubrication practice, not only for

1 We are indebted to E. F. Mueller, of the Bureau of Standards, for the suggestion to substitute a float valve for the safety reservoir.

12 Fluidity and Plasticity, McGraw Hill; 1922. 
greases but for oils at low temperatures as well will be reserved for subsequent publication.

Figure 5 is an example of the use of the instrument in obtaining flow-pressure diagrams on cup greases. The grease used here was of medium grade, showing a penetration of 241 at $77^{\circ} \mathrm{F}$. on the standard A. S. T. M. penetrometer. ${ }^{13}$ All of the data shown on Figure 5 were obtained without removing the instrument from the bath.

Before filling the consistometer to obtain the data of Figure 5 the grease was broken down in an A. S. T. M. grease worker to a constant

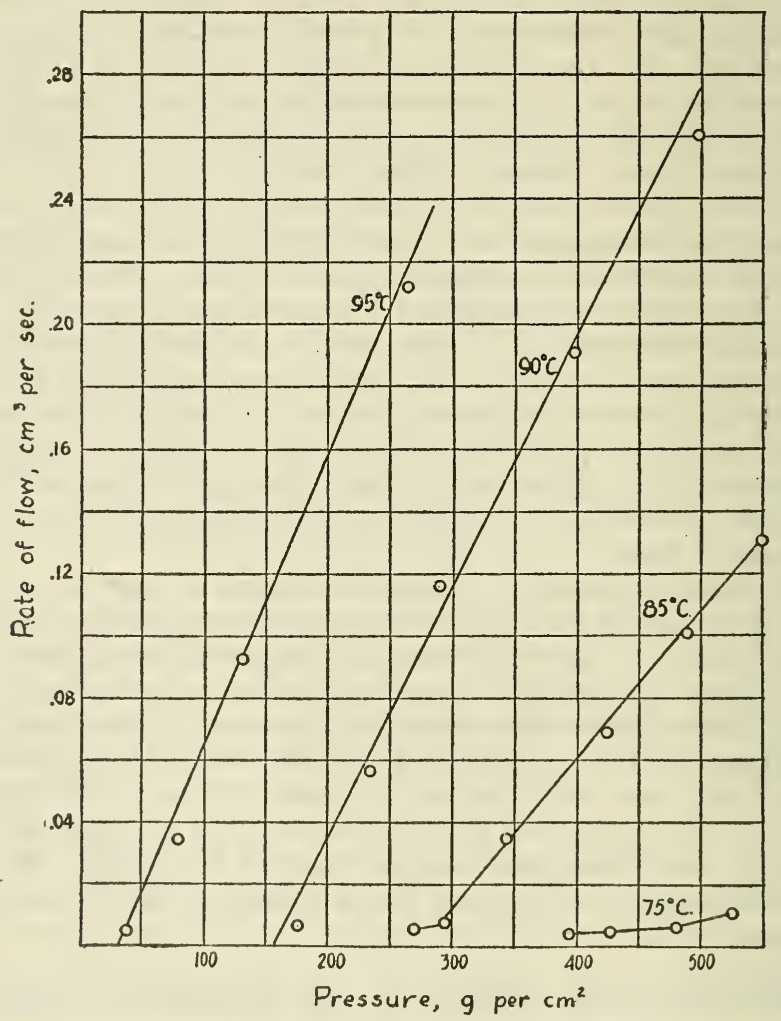

Figure 5.-Flow-pressure graphs on medium cup grease

consistency at room temperature. There was, consequently, no further breaking down of the grease as it passed through the capillary at the higher temperatures where the tests were made. Such would not be the case, however, for an oil or a grease cooled to a low temperature before test. To illustrate the unique utility of the instrument in such cases, Figures 6,7 , and 8 are given.

H. K. Griffin and S. A. McKee, in an unpublished investigation at the Bureau of Standards, have shown that a plastic oil cooled below its pour point does not at first flow at a steady rate through a consistometer capillary, even when the pressure producing flow is maintained 
constant. The rate instead gradually increases over a considerable period of time, but ultimately acquires a steady value, greatly in excess of that initially observed. This behavior was explained by Griffin and McKee as due to a breaking down of the structure of the congealed oil in the body of the consistometer before the material had yet arrived at the entrance to the capillary. The observations of Giesey and Arzoomanian, which must be explained in the same manner, have already been cited.

Figure 6 shows a test of a heavy paraffin-base oil with the instrument bere described. The oil was cooled in the instrument without any

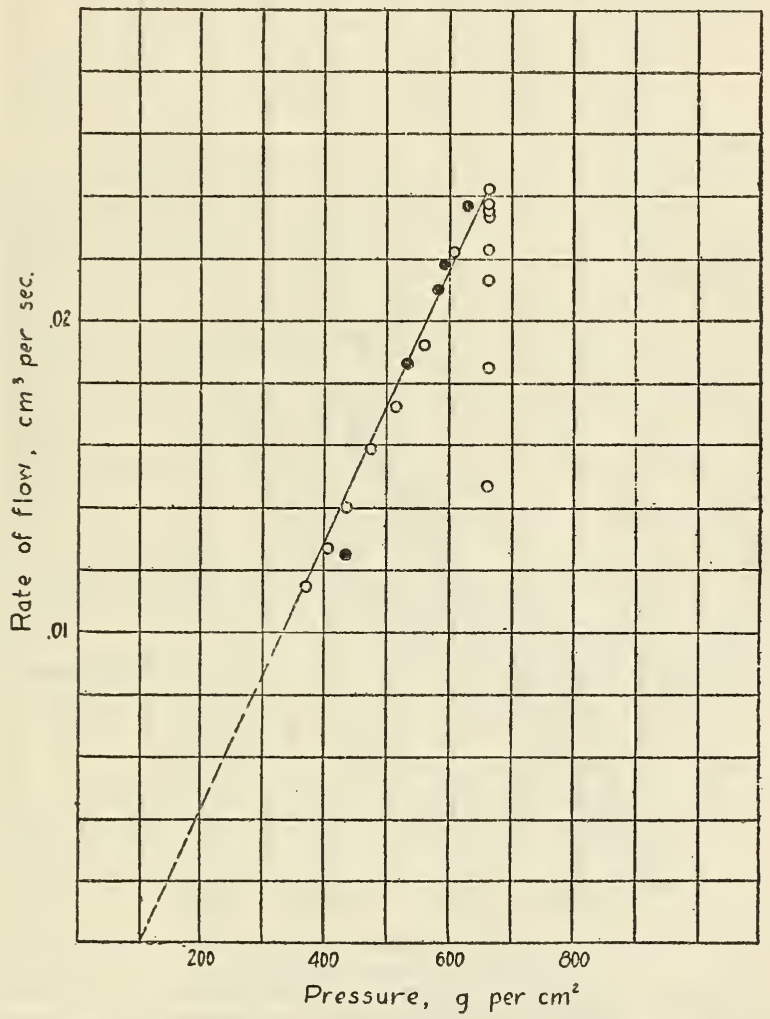

Figure 6.-Breakdown of a plastic oil before passing through capillary

disturbance for two hours before commencing the first test. An initial pressure of about $660 \mathrm{~g}$ per $\mathrm{cm}^{2}$ was applied and maintained while nine observations of the rate of flow were taken. The rate increased to about 170 per cent of its initial value before it became even approximately constant. The pressure was lowered through successive stages to give the graph represented by the empty circles, and was then increased and again lowered by steps to give the solid circles, all the points on the figure representing a single passage through the capillary. These graphs and many more of a similar nature which have been taken completely confirm the phenomenon observed by Griffin and McKee, as well as the interpretation they gave, 
In the instrument used by these investigators it was not possible to follow the breakdown process further. In the ordinary plastometer even this primary breakdown of structure completely escapes detection.

The far greater breakdown produced by passing the material through the capillary is shown by the triangles and crosses of Figure 7, which represent, respectively, the first and fifth passages of a plastic oil through the same capillary as employed in Figure 6 . The hook at the upper end of the graph represented by triangles is due to the

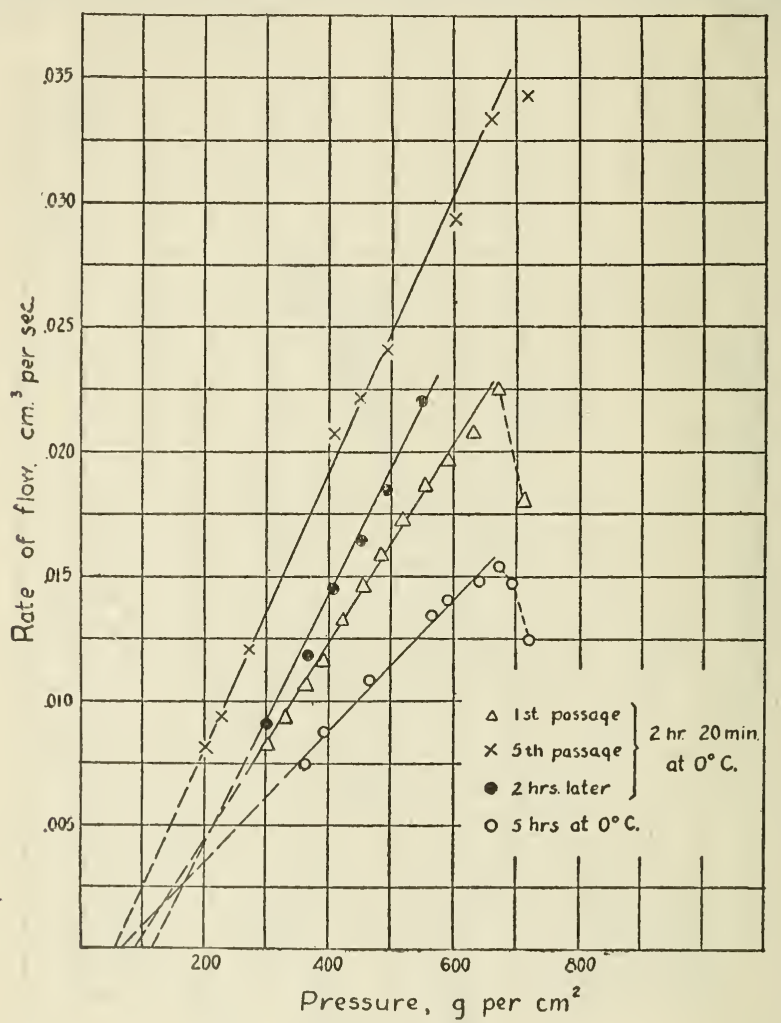

FIGURE 7.-Breakdown due to successive passages through capillary; also time effect of cooling

phenomenon shown in Figure 6, and indicates that the breakdown of the material is so great for the first part of the run that the rate of flow actually increases at first even though the pressure has been lowered somewhat. The same behavior has been observed in many other instances.

The solid circles of Figure 7 show that at a low temperature this oil possesses the property of thixotropy as already mentioned. Thus, after taking the data represented by crosses, the broken-down oil was allowed to stand at the same temperature undisturbed for two additional hours, when its resistance to flow was found to be greatly increased. The data represented by the empty circles were taken on a fresh sample of the same oil and show that the oil behaves somewhat like a glue or jelly in requiring a considerably longer time to 
reach its maximum stiffness than that required for it merely to assume the temperature of test. While, by actual measurement, it was known that less than 2 hours' standing in the bath was ample for all the oil to come to $0^{\circ} \mathrm{C}$., yet a sample cooled for 5 hours shows a much higher resistance to flow than the same oil cooled 2 hours and 20 minutes. These features emphasize the necessity of a standardized period of cooling for any lubricant on which a viscometric investigation is to be conducted at a low temperature.

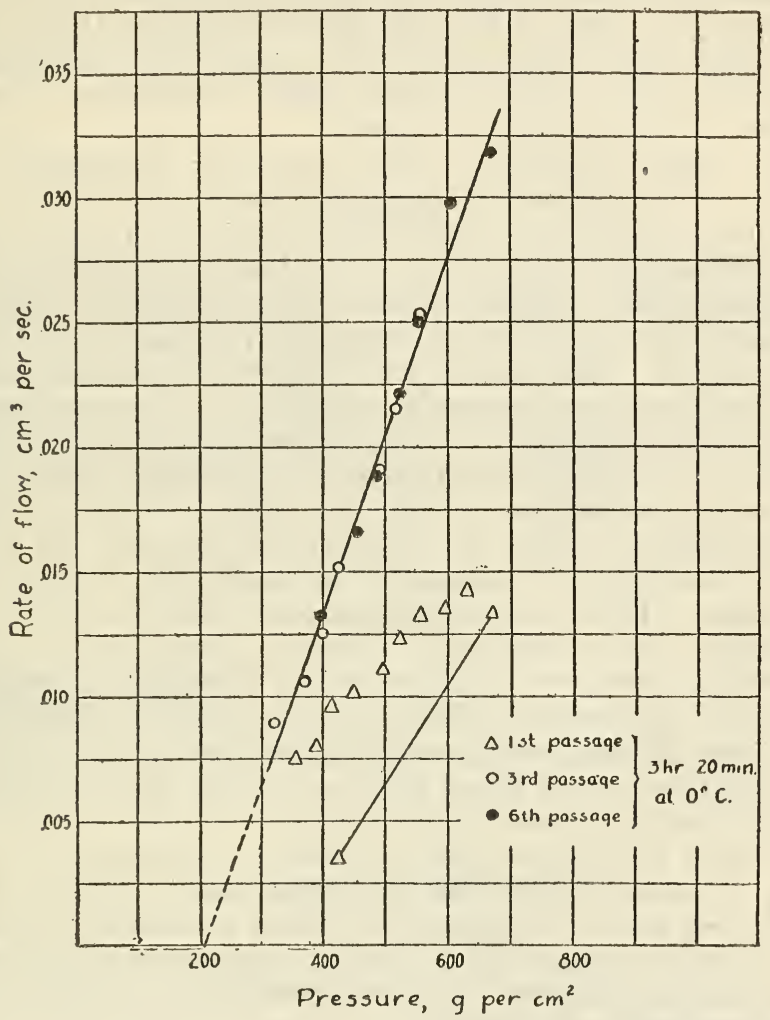

FIgURE 8.-Manner of obtaining both unworked and completely worked consistency

Before proceeding to Figure 8 it should be pointed out that of all the graphs on Figures 6 and 7 the only one which may possess any value whatsoever as a reproducible index of the consistency of the oil under test is the one shown by crosses on Figure 7, representing the fifth passage through the capillary. All the other graphs on these two figures represent data taken on a constantly changing material. For a graph to be of value as representing the consistency of a plastic oil under reproducible conditions, it must show either the consistency of the solid, undisturbed material or that of the oil thoroughly worked and broken down to a constant consistency.

Figure 8 shows how flow-pressure graphs for both these sets of circumstances may easily be obtained on the new instrument. Admittedly, the cooling period should be much longer than the three 
hours employed here if the data were to be used for other than illustrative purposes. The oil is cooled in the instrument the desired length of time without being disturbed. A single point is taken at a suitable pressure by forcing as small an amount of material as practicable through the capillary. The flow is stopped while the pressure is raised to a somewhat higher level and a second point is taken, again on a small amount of material. The total volume of flow for both points need not be in excess of $0.5 \mathrm{~cm}^{3}$. Since the flow-pressure graph of a grease or plastic oil is usually linear except at the lowest pressures, a straight line connecting these two points affords a satisfactory approximation to the true consistency of the solid, unworked oil. This is represented by the two triangles connected with a straight line on Figure 8.

A closer approximation to the unworked consistency could be obtained by correcting each of these two points downward, according to the scheme suggested by the data taken at constant pressure for Figure 6. That is to say, the total volume of material which has passed through the capillary might be determined when each of several separate rates of flow is measured, all the time keeping the pressure constant. The rates could then be plotted against the respective total volumes measured, and this curve extrapolated backward to zero volume of flow. The corresponding rate would represent very closely the starting rate of flow at the pressure employed.

The remaining triangles of Figure 8 show the data obtained by continuing the first passage of the material through the capillary in the manner which would ordinarily be employed to procure a flowpressure graph. These points are the ones which would be regarded as representing the consistency of the oil, were it not possible to make successive passages of the material through the capillary. It is evident that information of this type may be very misleading, since both the slope of the graph and its intercept on the pressure axis are vastly different from those obtained when tests are made either on the worked or the unworked material.

As illustrated by the two sets of circles on Figure 8, the worked consistency is measured on the new instrument simply by passing the oil back and forth through the capillary a number of times before taking the flow-pressure graph. To be assured that further working will not produce any further breaking down of the material, additional graphs may be taken as checks.

\section{CONCLUSIONS}

1. The consistometer described is speedy in operation and permits the taking of any number of flow-pressure graphs at the same or different temperatures without refilling or removing from the bath. It is suitable for materials which change in consistency with time or with mechanical working. It possesses the unusual advantage that it can be used to measure either the unworked or the worked consistency of plastic materials at any temperature. These are the properties generally recognized as most useful in characterizing such materials.

2. Certain oils at low temperatures show the property of thixotropy, and require a standardized period of cooling to assume a reproducible consistency.

Washington, November 19, 1929. 